\title{
Mission: Impossible?
}

\author{
Julien Garnon ${ }^{1}$
}

Received: 16 July 2020/ Accepted: 7 August 2020/Published online: 7 September 2020

(C) Springer Science+Business Media, LLC, part of Springer Nature and the Cardiovascular and Interventional Radiological Society of Europe (CIRSE) 2020

In the present issue, Winkelmann et al. [1] present their latest data about MRI guided microwave ablation of liver malignancies. Beyond the results, the case illustration taken from their experience highlights perfectly why MRI guidance has to be considered more than just an expensive fancy toy: it is possible to see the lesion even if it is small or in a difficult to target area such as the liver dome; it is also possible to differentiate the treated tumor and the surrounding necrotic area, thereby providing immediate feedback on the size of the safety margins which is the most important prognostic factor for the success of a liver ablation. Moreover, the precision of needle positioning is guaranteed by its advancement under real-time multiplanar MR fluoroscopy. All at a cost of a complete radiation-free procedure! But it is not just about microwave and liver. Radiofrequency, laser, high-focused ultrasound and cryoablation can be used in an MR suite provided that the devices are compatible with the ferromagnetic environment. Many other organs can benefit from the advantages of MRI-guidance as already reported in the literature: kidney, prostate, soft tissue, and even bone (Fig. 1) [2-4]. With MRI guidance you are not guessing that the ablation is complete or that the surrounding organs have been preserved: you can actually see it anytime during the intervention. On the other hand, this is currently not without limitations. In their initial experience treating hepatic tumors with MR-guided microwave ablation, Hoffmann et al. [5] were struggling with a low power generator that

Julien Garnon

juliengarnon@gmail.com

1 Department of Interventional Radiology, Nouvel Hôpital Civil, 1, place de l'hôpital, 67096 Strasbourg Cedex, France led to a significantly higher rate of applicator repositioning and procedural time compared to the present study. Development of a high-power microwave generator enabled the same team to improve the quality of treatment. This underlines that significant efforts are still to be made to impose MRI as a cutting-edge technology. Planification and guidance softwares, dedicated interventional coils, specific technician training, MR-compatible respirators, needles, probes and devices, etc., all these need to be developed, upgraded and standardized to improve the users' experience. MRI-guided interventions are still a niche market and are therefore associated with limited developments by the manufacturers and limited usability for the radiological staff. Accessibility to the machines and high costs are additional major limitations to access MRIguidance in a clinical practice. So, MRI-guided thermal ablation: mission impossible? Looking back at more than 50 years of technical innovations in interventional radiology, this is unlikely. Creativity and tenacity certainly qualify our specialty and our mission, should we choose to accept it, is to bring that technology to the next level. Not (only) for fun but to carry on with the development of interventional radiology. Be reassured, this commentary will not self-destruct before you went through the manuscript from Winkelmann et al. in the present issue.

\section{Funding None.}

Compliance with Ethical Standards

Conflict of interest Canon Medical, J\&J, Medtronic: fees for oral presentation; Boston-BTG: proctor. 

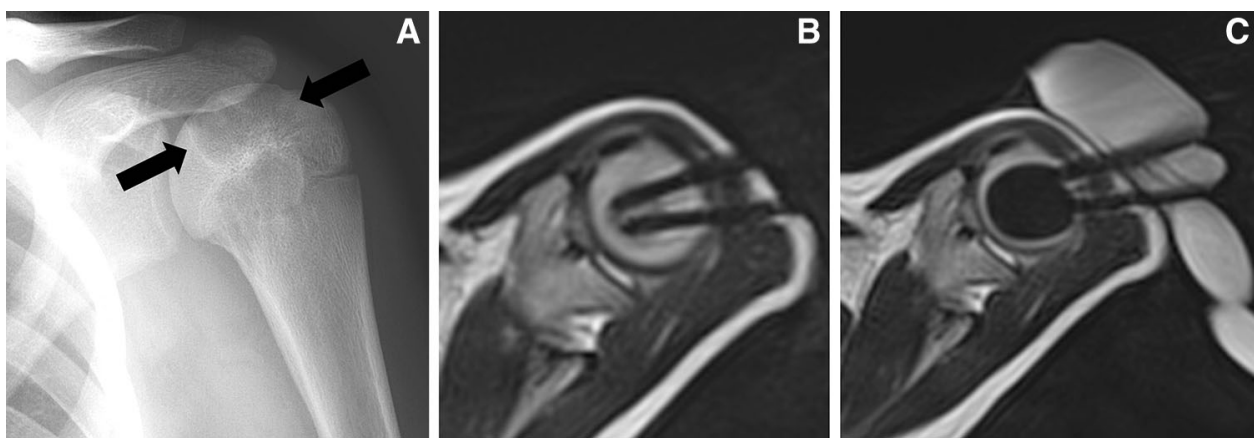

Fig. 1 MRI-guided cryoablation of a humeral chondroblastoma. a plain film showing an osteolytic tumor in the humeral head close to the joint (arrows). b axial T2 MRI following insertion of two cryoprobes inside the tumor. c axial T2 MRI depicting the iceball as a

\section{References}

1. Winkelmann MT, Gohla G, Kübler J, et al. MR-guided high-power microwave ablation in hepatic malignancies: initial results in clinical routine. Cardiovasc Intervent Radiol. 2020;10:12. https:// doi.org/10.1007/s00270-017-1799-6.

2. Kinsman KA, White ML, Mynderse LA, et al. Whole-gland prostate cancer cryoablation with magnetic resonance imaging guidance: one-year follow-up. Cardiovasc Intervent Radiol. 2018;41(2):344-9. https://doi.org/10.1007/s00270-017-1799-6.

3. Ahrar K, Ahrar JU, Javadi S, et al. Real-time magnetic resonance imaging-guided cryoablation of small renal tumors at $1.5 \mathrm{~T}$. Invest Radiol. 2013;48(6):437-44. https://doi.org/10.1097/RLI. $0 \mathrm{~b} 013 \mathrm{e} 31828027 \mathrm{c} 2$. signal void which is covering the tumor without involving the joint. Such visualization of the ice inside the trabecular bone would not have been possible with $\mathrm{CT}$ scan

4. Thompson SM, Callstrom MR, McKusick MA, Woodrum DA. Initial results of image-guided percutaneous ablation as secondline treatment for symptomatic vascular anomalies. Cardiovasc Intervent Radiol. 2015;38(5):1171-8. https://doi.org/10.1007/ s00270-015-1079-2.

5. Hoffmann R, Rempp H, Keßler DE, et al. MR-guided microwave ablation in hepatic tumours: initial results in clinical routine. Eur Radiol. 2017;27(4):1467-76. https://doi.org/10.1007/s00330-0164517-x.

Publisher's Note Springer Nature remains neutral with regard to jurisdictional claims in published maps and institutional affiliations. 